\title{
BMJ Open Domestic violence: a cross-sectional study among pregnant women in different regions of Sri Lanka
}

\author{
Munas M Muzrif, ${ }^{1}$ Dinusha Perera, ${ }^{1}$ Kumudu Wijewardena, ${ }^{1}$ Berit Schei, ${ }^{2,3}$ \\ Katarina Swahnberg ${ }^{4}$
}

To cite: Muzrif MM, Perera D, Wijewardena K, et al. Domestic violence: a cross-sectional study among pregnant women in different regions of Sri Lanka. BMJ Open 2018;8:e017745. doi:10.1136/ bmjopen-2017-017745

- Prepublication history for this paper is available online. To view these files, please visit the journal online (http://dx.doi. org/10.1136/bmjopen-2017017745).

Received 14 May 2017 Revised 14 December 2017 Accepted 14 December 2017

Check for updates

${ }^{1}$ Department of Community Medicine, Faculty of Medical Sciences, University of Sri Jayawardenapura, Colombo, Sri Lanka

${ }^{2}$ Department of Public Health and Nursing, Faculty of Medicine and Health Sciences, Norwegian University of Science and Technology (NTNU), Trondheim, Norway

${ }^{3}$ Department of Obstetrics and Gynecology, St. Olavs Hospital Trondheim University Hospital, Trondheim, Norway ${ }^{4}$ Department of Health and Caring Sciences, Faculty of Health and Life Science, Linnaeus University, Kalmar, Sweden

Correspondence to Dr Munas M Muzrif; muzrif@gmail.com

\section{ABSTRACT}

Objectives The aims of this study were to assess the regional differences in domestic violence among pregnant women in the capital district and in the tea plantation sector of Sri Lanka, to explore potential contributory factors and to assess whether healthcare workers addressed domestic violence and disclosure among survivors.

Design A cross-sectional study was carried out using interviewer-administered Abuse Assessment Screen.

Setting Fifty-seven antenatal clinic centres in the capital district and 30 in the tea plantation sector.

Participants Pregnant women between 6 and 40 weeks of gestational age. In the capital district, 1375 women were recruited from antenatal clinic centres in the urban $(n=25)$ and in the rural areas $(n=32)$, and 800 women from 30 centres in the tea plantation sector. The response rate in the capital district was $95.6 \%$ and $96.7 \%$ in the tea plantation sector.

Results Among the total sample of pregnant women $(n=2088)$, the prevalence of 'ever abused' was $38.6 \%$, and the prevalence of 'currently abused' was $15.9 \%$. 'Ever abused' (31.5\% vs $50.8 \%)$ and 'currently abused' (10\% vs $25.8 \%)$ were significantly higher $(\mathrm{P}<0.001)$ among the women living in the tea plantation sector. 'Ever abused' was associated with living in the tea plantation sector, being employed, living far from gender-based violence care centre and of Muslim ethnicity, after adjusting for age, education and family income. Only $38.8 \%$ of all participants had been asked by healthcare workers about abuse. Living in the tea plantation sector and lower level of education were associated with not being asked. Among those who reported 'ever abused', only $8.7 \%$ had disclosed the experience to a healthcare worker.

Conclusion Domestic violence was prevalent and highest among women in the tea plantation sector compared with the capital district. The capacity of healthcare workers in addressing domestic violence should be increased.

\section{INTRODUCTION}

Despite great advances achieved by Sri Lankan women, in terms of quality of life during recent decades, many disparities, discriminations and violation of women's rights persist. Sri Lankan women's health and non-health aspects are compromised by pervasive domestic violence (DV) in all spheres of their

\section{Strengths and limitations of this study}

This is the first large-scale study comparing estimates of domestic violence in different settings in Sri Lanka.

- An adequate sample was recruited through a thorough sampling technique. Furthermore, high response rate and well-established tools for data collection ensure the validity of data and that the results can be generalised to similar settings in Sri Lanka.

- Despite undertaking several measures such as securing confidentiality and having female data collectors, under-reporting is possible due to the sensitive nature of the study area.

The retrospective study design could have resulted in recall bias.

lives. It has become increasingly evident that issues of DV have to be addressed if we are to further improve the well-being of the women and thereby the lives of the entire community in Sri Lanka. ${ }^{1}$ The term 'domestic violence' covers violence against women by an intimate partner or by other cohabitants of the family, wherever this violence takes place and in whatever type of violence.

Prevalence surveys over the past three decades have produced estimates of DV, ranging from $18 \%$ to $72 \%$ in different study settings and populations in Sri Lanka. ${ }^{2-8}$ Among these, only one study has been conducted exclusively among pregnant women. ${ }^{5}$ The population in the capital district is mostly Sinhalese and Buddhist and consists of highly urban, rural geographical localities, and also agricultural estates. ${ }^{9}$ The Badulla district is in the central hill country of Sri Lanka. The economy of the district is mostly dependent on tea, and other agricultural products. The population in the tea plantation sector in the Badulla district is mostly Indian Tamils. ${ }^{9}$ In contrast to the capital district, the tea estate population is considered as the poorest and as a vulnerable 
Table 1 Background characteristics of the antenatal women in the capital district and the tea plantation sector of Sri Lanka

\begin{tabular}{|c|c|c|c|c|}
\hline & Total & Capital district & Tea plantation sector & \\
\hline & $\mathrm{n}=2088(\%)$ & $\mathrm{n}=1314(\%)$ & $\mathrm{n}=774(\%)$ & $P$ value \\
\hline \multicolumn{5}{|l|}{ Women's characteristics } \\
\hline \multicolumn{5}{|l|}{ Age } \\
\hline $16-30$ years & $1125(53.9)$ & $559(42.5)$ & $566(73.1)$ & \\
\hline $31-44$ years & $963(46.1)$ & $755(57.5)$ & $208(26.9)$ & $P<0.001$ \\
\hline \multicolumn{5}{|l|}{ Education* } \\
\hline Low & $1242(59.5)$ & 564 (42.9) & $678(87.6)$ & \\
\hline High & $846(40.5)$ & $750(57.1)$ & $96(12.4)$ & $P<0.001$ \\
\hline \multicolumn{5}{|l|}{ Ethnicity } \\
\hline Sinhala & $986(47.2)$ & 967 (73.6) & $19(2.5)$ & \\
\hline Tamil & $910(43.6)$ & $166(12.6)$ & $744(96.1)$ & \\
\hline Muslim & $181(8.7)$ & $170(12.9)$ & $11(1.4)$ & \\
\hline Others/missing & $11(0.5)$ & $11(0.8)$ & $0(0.0)$ & $P<0.001$ \\
\hline \multicolumn{5}{|l|}{ Employment status } \\
\hline Employed & $630(30.2)$ & $271(20.6)$ & $359(46.4)$ & \\
\hline Unemployed & $1458(69.8)$ & $1043(79.4)$ & $415(53.6)$ & $P<0.001$ \\
\hline \multicolumn{5}{|l|}{ Marital status } \\
\hline Currently married & 2073 (99.3) & 1307 (99.5) & $766(99.0)$ & \\
\hline Living together & $12(0.6)$ & $6(0.5)$ & $6(0.8)$ & \\
\hline Other & $3(0.1)$ & $1(0.1)$ & $2(0.3)$ & $P=0.368$ \\
\hline \multicolumn{5}{|l|}{ Partners characteristics } \\
\hline \multicolumn{5}{|l|}{ Education* } \\
\hline Low & $1251(59.9)$ & $554(42.2)$ & $697(90.1)$ & \\
\hline High & $837(40.1)$ & $760(57.8)$ & $77(9.9)$ & $P<0.001$ \\
\hline \multicolumn{5}{|l|}{ Other characteristics } \\
\hline \multicolumn{5}{|l|}{ Employment status } \\
\hline Employed & 2060 (98.7) & $1291(98.2)$ & $769(99.4)$ & \\
\hline Unemployed & $28(1.3)$ & $23(1.8)$ & $5(0.6)$ & $P=0.034$ \\
\hline \multicolumn{5}{|l|}{ Monthly income of family } \\
\hline Low (up to 30000 SLR) & $1581(75.7)$ & $908(69.1)$ & $673(87.0)$ & \\
\hline Middle (30001-50 000 SLR) & $375(18.7)$ & $283(21.5)$ & $92(11.9)$ & \\
\hline High (>50 000 SLR) & $132(6.3)$ & $123(9.4)$ & $9(1.2)$ & $P<0.001$ \\
\hline
\end{tabular}

*Education-low (no schooling and primary-level school education only) and high (above primary-level school education).

population in the country. Almost all the health indicators for estate sector are below the level of the Colombo district. $^{1011}$

In Sri Lanka, treatment for injuries and complications following DV is offered in all hospitals, while special services such as counselling and psychosocial support for the survivors are provided in specialised institutions. Public health midwives (PHMs) are the designated grass root level public health workers who are responsible for providing maternal and child healthcare. They work at the community level and serve a population of approximately 3000-5000 in a PHM area. Women are not routinely asked about experiences of DV, but these PHMs are especially trained to recognise and provide services to the survivors of DV in the community. ${ }^{12}$

Since 2007, the Ministry of Health of Sri Lanka commenced a process of establishing hospital-based gender-based violence (GBV) care centres. One such centre is Mithuru Piyasa, located in an easily accessible outpatient and emergency care setting within hospitals. Women may be self-identified as needing services or may be referred by healthcare staff from the preventive or curative health sector. ${ }^{13}$ The GBV care centre model is similar to certain characteristics of 'one-stop crisis centres' in other countries such as Malaysia, Thailand and India. ${ }^{1415}$ 
Table 2 Prevalence of emotional, physical and sexual abuse among antenatal women in the capital District and the tea plantation sector of Sri Lanka

\begin{tabular}{|c|c|c|c|c|}
\hline & \multirow{2}{*}{$\begin{array}{l}\text { Total } \\
\mathrm{n}=2088(\%) \\
\end{array}$} & \multirow{2}{*}{$\begin{array}{l}\text { Capital district } \\
\mathrm{n}=1314(\%)\end{array}$} & \multirow{2}{*}{$\begin{array}{l}\text { Tea plantation } \\
\mathrm{n}=774(\%)\end{array}$} & \multirow[b]{2}{*}{$P$ value } \\
\hline & & & & \\
\hline \multicolumn{5}{|c|}{$\begin{array}{l}\text { Have you ever been afraid of anyone within } \\
\text { your family? }\end{array}$} \\
\hline Yes & $508(24.4)$ & $174(13.2)$ & 334 (43.3) & \\
\hline No & $1577(75.6)$ & $1140(86.8)$ & $437(56.7)$ & $P<0.001$ \\
\hline \multicolumn{5}{|c|}{$\begin{array}{l}\text { Have you ever been emotionally or physically } \\
\text { abused by someone important to you in the } \\
\text { family? }\end{array}$} \\
\hline Yes & 757 (36.3) & $399(30.4)$ & $358(46.3)$ & \\
\hline No & $1331(63.7)$ & 915 (69.6) & $416(53.7)$ & $P<0.001$ \\
\hline \multicolumn{5}{|c|}{$\begin{array}{l}\text { Within the last year, have you been hit, } \\
\text { slapped, kicked or otherwise physically hurt } \\
\text { by someone in the family? }\end{array}$} \\
\hline Yes & $316(15.1)$ & $120(9.1 \%)$ & $196(25.3 \%)$ & \\
\hline No & $1772(84.9)$ & 1194 (90.9\%) & $578(74.7 \%)$ & $P<0.001$ \\
\hline \multicolumn{5}{|c|}{$\begin{array}{l}\text { Within the last year has anyone in the family } \\
\text { forced you to have sexual activities? }\end{array}$} \\
\hline Yes & $37(1.8)$ & $22(1.7)$ & $15(1.9)$ & \\
\hline No & $2051(98.2)$ & $1292(98.3 \%)$ & $759(98.1)$ & $P=0.66$ \\
\hline \multicolumn{5}{|c|}{$\begin{array}{l}\text { Since you have been pregnant, have you been } \\
\text { hit, slapped, kicked or otherwise physically } \\
\text { hurt by someone in the family? }\end{array}$} \\
\hline Yes & $134(6.4)$ & $53(4.0)$ & $81(10.5)$ & \\
\hline No & 1954 (93.6) & 1261 (96.0) & $693(89.5)$ & $P<0.001$ \\
\hline \multicolumn{5}{|c|}{ Ever abused * } \\
\hline Yes & 807 (38.6) & $414(31.5)$ & $393(50.8)$ & \\
\hline No & $1281(61.4)$ & $900(68.5)$ & $381(49.2)$ & $P<0.001$ \\
\hline \multicolumn{5}{|c|}{ Currently abused $\dagger$} \\
\hline Yes & $332(15.9)$ & $132(10.0)$ & $200(25.8)$ & \\
\hline No & $1756(84.1)$ & $1182(90.0)$ & $574(74.2)$ & $P<0.001$ \\
\hline \multicolumn{5}{|c|}{ Distanceł } \\
\hline Near & $1173(56.2)$ & 1077 (82.0) & $96(12.4)$ & \\
\hline Far & $915(43.8)$ & $237(18.0)$ & $678(87.6)$ & $P<0.001$ \\
\hline \multicolumn{5}{|c|}{$\begin{array}{l}\text { Ever being asked by a healthcare worker } \\
\text { about abuse }\end{array}$} \\
\hline Ever & $810(38.8)$ & $726(55.3)$ & 84 (10.9) & \\
\hline Never & $1278(61.2)$ & $588(44.7)$ & $690(89.1)$ & $P<0.001$ \\
\hline
\end{tabular}

\section{Disclosure of abuse to a healthcare worker} among 'ever abused'

\begin{tabular}{lcccc} 
& $\mathbf{N} \S=\mathbf{7 9 1}(\%)$ & $\mathbf{n = 4 1 3 ( \% )}$ & $\mathbf{n = 3 7 8 ( \% )}$ \\
Ever & $69(8.7)$ & $55(13.3)$ & $14(3.7)$ & \\
Never & $722(91.3)$ & $358(86.7)$ & $364(96.3)$ & $P<0.001$ \\
\hline
\end{tabular}

*Ever abused-ever been emotionally or physically abused and/or physically abused last year and/or physically abused during pregnancy and/or sexually abused last year were combined and labelled as 'ever abused'.

†Currently abused-physically abused last year and/or sexually abused last year were combined and labelled as 'currently abused'. fDistance from the residence to the nearest gender-based violence care centre-near $(<11 \mathrm{~km})$ and far $(>11 \mathrm{~km})$.

§Although the number of 'ever abused' was 807 , a total of 791 participants had responded to the particular question regarding disclosure. 
Table 3 Crude and adjusted OR for 'ever-abused' and associated factors adjusted for all included variables

\begin{tabular}{|c|c|c|c|c|}
\hline & OR $_{\text {crude }}$ & $\mathrm{Cl}(95 \%)$ & OR $_{\text {Adjusted }}$ & $\mathrm{Cl}(95 \%)$ \\
\hline \multicolumn{5}{|c|}{ Women's characteristics } \\
\hline \multicolumn{5}{|l|}{ Living area } \\
\hline Tea plantation sector & 2.24 & 1.87 to 2.70 & 1.62 & 1.11 to 2.37 \\
\hline Capital district & 1 & & 1 & \\
\hline \multicolumn{5}{|l|}{ Age } \\
\hline $16-30$ years & 1.48 & 1.24 to 1.77 & 1.18 & 0.97 to 1.43 \\
\hline $31-44$ years & 1 & & 1 & \\
\hline \multicolumn{5}{|l|}{ Ethnicity } \\
\hline Tamils & 2.02 & 1.68 to 2.44 & 0.90 & 0.65 to 1.27 \\
\hline Muslims & 1.54 & 1.11 to 2.13 & 1.51 & 1.08 to 2.11 \\
\hline Sinhalese & 1 & & 1 & \\
\hline \multicolumn{5}{|l|}{ Education ${ }^{* *}$} \\
\hline Low & 1.64 & 1.37 to 1.97 & 1.08 & 0.84 to 1.39 \\
\hline High & 1 & & 1 & \\
\hline \multicolumn{5}{|l|}{ Employment } \\
\hline Employed & 1.39 & 1.15 to 1.68 & 1.25 & 1.01 to 1.55 \\
\hline Housewife & 1 & & 1 & \\
\hline \multicolumn{5}{|c|}{ Partner's characteristics } \\
\hline \multicolumn{5}{|l|}{ Education* } \\
\hline Low & 1.68 & 1.40 to 2.02 & 1.15 & 0.89 to 1.49 \\
\hline High & 1 & & 1 & \\
\hline \multicolumn{5}{|c|}{ Other characteristics } \\
\hline Family income & 1.35 & 1.10 to 1.67 & 1.11 & 0.87 to 1.42 \\
\hline \multicolumn{5}{|l|}{$\operatorname{Low}(<30000$ SLR $)$} \\
\hline Middle and high & 1 & & 1 & \\
\hline \multicolumn{5}{|l|}{ Distance† } \\
\hline Far & 2.07 & 1.73 to 2.47 & 1.44 & 1.13 to 1.84 \\
\hline Near $(<11 \mathrm{~km})$ & 1 & & 1 & \\
\hline
\end{tabular}

*Education-low (no schooling and primary-level school education only) and high (above primary-level school education).

†Distance from the residence to the nearest gender-based violence care centre.

One study conducted in the capital province of Sri Lanka among women who have ever been married revealed that in spite of the freely available services, more than half of the survivors did not reveal the violent experiences to anyone. The reasons for not disclosing included embarrassment, concerns about reputation and fear of more violence. Some women had accepted violence as a normative behaviour. ${ }^{2}$

There are no large-scale studies that compare prevalence of DV in various settings in Sri Lanka, and data on the prevalence of DV in the tea plantation sector are lacking. Moreover, there are no estimates on how frequently healthcare staffs routinely inquire about DV.

Therefore, the aim of this study was to assess the regional differences in DV among pregnant women in the capital district (Colombo) and in the tea plantation sector (Badulla) of Sri Lanka. We also wanted to assess factors associated with DV and being asked about DV or not, and whether survivors had disclosed DV to any healthcare professional.

\section{METHODOLOGY}

For this cross-sectional study, the data were collected during April to December 2014. The study population of the two study settings included currently pregnant women registered by PHMs. Multistage cluster sampling strategy was used to identify pregnant women from the Colombo district and from the tea plantation sector in Badulla. In Sri Lanka, all the districts are divided into Medical Officer of Health $(\mathrm{MOH})$ areas; the administrative divisions of public health and the $\mathrm{MOH}$ areas are subdivided into the smallest public health administrative areas, known as PHM areas. At stage 1, the $\mathrm{MOH}$ areas were randomly selected from each sector. In the second stage relating to the PHM areas, the primary sample units were randomly 
Table 4 Crude and adjusted OR for 'not being asked by a healthcare worker about abuse' and associated factors adjusted for all included variables

\begin{tabular}{|c|c|c|c|c|}
\hline & $\mathbf{O R}_{\text {crude }}$ & $\mathrm{Cl}(95 \%)$ & OR $\mathbf{R}_{\text {Adjusted }}$ & $\mathrm{Cl}(95 \%)$ \\
\hline \multicolumn{5}{|l|}{ Ever abused } \\
\hline Yes & 1.25 & 1.04 to 1.50 & 0.82 & 0.66 to 1.02 \\
\hline No & 1 & & 1 & \\
\hline \multicolumn{5}{|l|}{ Women's characteristics } \\
\hline \multicolumn{5}{|l|}{ Age (years) } \\
\hline $16-30$ years & 1.69 & 1.41 to 2.02 & 0.93 & 0.75 to 1.14 \\
\hline $31-44$ years & 1 & & 1 & \\
\hline \multicolumn{5}{|l|}{ Education* } \\
\hline Low & 3.83 & 3.18 to 4.61 & 1.98 & 1.58 to 2.47 \\
\hline High & 1 & & 1 & \\
\hline \multicolumn{5}{|l|}{ Employment } \\
\hline Housewife & 0.77 & 0.63 to 0.94 & 1.38 & 1.07 to 1.78 \\
\hline Employed & 1 & & 1 & \\
\hline \multicolumn{5}{|l|}{ Geography } \\
\hline \multicolumn{5}{|l|}{ Living area } \\
\hline Tea plantation sector & 10.14 & 7.89 to 13.04 & 9.06 & 6.42 to 12.80 \\
\hline Capital district & 1 & & 1 & \\
\hline \multicolumn{5}{|l|}{ Other characteristics } \\
\hline \multicolumn{5}{|l|}{ Family income } \\
\hline Low (<30000 SLR) & 1.81 & 1.48 to 2.22 & 0.90 & 0.70 to 1.16 \\
\hline Middle and high & 1 & & 1 & \\
\hline \multicolumn{5}{|l|}{ Distance† } \\
\hline $\operatorname{Far}(<11 \mathrm{~km})$ & 3.65 & 3.01 to 4.43 & 1.01 & 0.78 to 1.32 \\
\hline Near & & 1 & & \\
\hline
\end{tabular}

*Education-low (no schooling and primary-level school education only) and high (above primary-level school education).

†Distance from the residence to the nearest gender-based violence care centre.

selected from each $\mathrm{MOH}$ area. Among the pregnant women, those who had been registered by PHMs were eligible to participate in the study. A cluster consisted of 25 pregnant women who were randomly selected from the PHMs' regularly updated register of pregnant mothers. Sample size was calculated separately for both settings, using standard methods and adjusted for a non-response rate of $10 \%$ and design effect. ${ }^{16} 17$ A total of 1375 pregnant women from 57 PHM areas in Colombo and 800 from 30 PHM areas in Badulla were eligible to participate in the study, and they were recruited during their visits to the field antenatal clinics.

The main survey instrument, the Abuse Assessment Screen (AAS) ${ }^{18}$ consisted of specific questions on violence against women, within their lifetime, within the past 12 months, and specifically during pregnancy, by members of the household. The prevalence of ever being subjected to physical, sexual and/or emotional violence during the last year and during pregnancy was explored. Furthermore, women were questioned as to whether a healthcare worker had 'ever asked them about abuse' and among those reporting DV, women were asked whether they had ever disclosed the abuse to a healthcare worker. The distance from the living area to a GBV care centre was assessed and recoded as near or far $(>11 \mathrm{~km})$.

AAS was translated into Sinhalese and Tamil, the local languages spoken by the majority of the population, using the translation-back translation method and adapted to suit the local dialect. Another questionnaire was developed to obtain the sociodemographic characteristics (age, religion, ethnicity, level of education, employment status) of the respondents. Both survey instruments were assessed for face and content validity.

Female data collectors with training on social work, research and counselling were recruited and trained. Informed written consent was obtained from each of the respondents. Data collection took place by conducting interviews in the field antenatal clinics, where it was possible to ensure privacy, confidentiality and safety. Following the interviews, the respondents were offered contact and referral information for centres providing services to survivors of violence.

For analytical purposes, ever been emotionally or physically abused and/or physically abused last year and/ 
or physically abused during pregnancy and/or sexually abused last year among pregnant women were combined and labelled as 'ever abused'. Physically abused last year and/or sexually abused last year were combined and labelled as 'currently abused'. The statistical analysis of prevalence estimates and multivariate analysis using logistic regression to identify the adjusted correlates for 'ever abused' and for 'ever being asked by a healthcare worker about abuse' was conducted using the Statistical Package for Social Sciences (SPSS) V.21. First, the characteristics were compared at the univariate level; thereafter, factors that were statistically significant $(\mathrm{P}<0.05)$ were included in the logistic regression model.

\section{RESULTS}

Out of the 2175 eligible antenatal women selected for the survey, 96\% (2088/2175) consented to participate, and these women were not in any way different from the non-respondents. The mean age of women was 29.63 years (SD 5.57), and the majority belonged to the Sinhala $(47.2 \%)$ and Tamil $(43.6 \%)$ ethnic groups. More than half $(59.5 \%)$ of the women had completed $<11$ years of school education, and about $70 \%$ were housewives (unemployed). Almost all $(99.3 \%)$ the women were married at the time of the interview. However, all background characteristics except 'marital status' differed significantly between the two settings (table 1 ).

Average distance from the women's living area (PHM area or estate) to the nearest GBV care centre was assessed. Eighteen per cent of the women from the capital district and $87.7 \%$ from the tea plantation sector were living far from a GBV care centre, and this difference was significant (table 1).

DV was commonly reported in both study settings. However, all the estimates on DV except sexual violence were significantly higher among women in the tea plantation sector compared with the capital district. Prevalence of 'ever abused' was $38.6 \%$ in the total sample, with $50.8 \%$ in the tea plantation sector and $31.5 \%$ in the capital district. Prevalence of 'currently abused' was $15.9 \%$ in the total sample, with $25.8 \%$ in the tea plantation sector and $10.0 \%$ in the capital district (table 2).

In the logistic regression model, study setting was included as a separate variable. Living in the tea plantation sector (OR 1.62, CI 1.11 to 2.37), being employed (OR 1.25, CI 1.01 to 1.55), living far from a GBV care centre (OR 1.44, CI 1.13 to 1.84 ) and Muslim ethnicity (OR 1.51, CI 1.08 to 2.11) compared with Sinhalese ethnicity were significantly associated with 'ever abused', after adjusting for age, education level of woman and man as well as family income (table 3 ).

Compared with the capital district (13.3\%), disclosure among those 'ever abused' was significantly less common in the tea plantation sector (3.7\%) (table 2). In a separate analysis, it was revealed that among those 'ever abused' $(\mathrm{n}=807)$, only $35.6 \%(\mathrm{n}=288)$ had 'ever been asked by a healthcare worker about abuse' and among these $35.6 \%$ $(\mathrm{n}=288)$, only $12.5 \% \quad(\mathrm{n}=36)$ had disclosed the abusive experience to a healthcare worker.

Living in the tea plantation sector (OR 9.06, CI 6.42 to 12.80), the woman's lower level of education (no schooling and school education at primary level only) (OR 1.98, CI 1.58 to 2.47) and being a housewife (unemployed) (OR 1.38 , CI 1.07 to 1.78 ) were significantly associated with 'not being asked by a healthcare worker about abuse' after adjusting for 'ever abused', age, family income and distance from the GBV care centre (table 4).

\section{DISCUSSION}

The current study was conducted in the Colombo district, the administrative and commercial capital of Sri Lanka, and in the tea plantation sector in the Badulla district. This is the first large-scale study comparing the estimates of DV in different settings in Sri Lanka. All the estimates on DV except sexual violence were significantly higher among the women in the tea plantation sector compared with the capital district. Living area was also strongly associated with 'not being asked by a healthcare worker about abuse' as well as education and employment status. Among those who reported 'ever abused', only a small proportion had disclosed the abusive experiences to a healthcare worker.

There are no optimal previous estimates for comparisons from either setting. However, when comparing the available data, our estimates are lower in the capital district and higher in the tea plantation sector than previously reported. ${ }^{2} 4$ In previous studies from the capital district, differences in the sample characteristics and survey instruments are potential explanations. For example, in the study by Jayasuriya, ${ }^{2}$ the study population included women who had ever been married, while currently pregnant women were included in this study. Lower estimates in the previous studies from Badulla could be partly due to the exclusion of the most vulnerable population in the tea plantation sector of Badulla district. Furthermore, using healthcare providers who were familiar to the participants for data collection may have contributed to the low estimates. In this study, the data collectors were well-trained female interviewers who were not familiar to the participants.

Notably, sexual abuse (last year) was reported at a low rate $(<2 \%)$ in both settings. Despite undertaking several measures such as securing confidentiality and having female data collectors, under-reporting is possible due to the sensitive nature and cultural taboos surrounding sexual abuse.

Living in the tea plantation sector compared with the capital district, living far from a GBV care centre, being of Tamil and Muslim ethnicity compared with Sinhalese ethnicity and being employed compared with being a housewife were factors significantly associated with reporting 'ever abused' after adjusting for age, educational level of woman and man, and family income. Being employed is more common among women in the tea 
plantation sector $(46 \%)$ compared with the capital district $(20 \%)$. Unskilled labourers are the main workforce in the tea plantation sector in contrast to skilled labourers and professionals in the capital district.

The tea plantation sector is comparatively less developed than the capital district. Differences in socioeconomic and cultural aspects may have contributed to the higher estimates of DV in the tea plantation sector. For example, higher estimates of DV were found among the Muslim and Tamil ethnic groups than the Sinhalese, and Tamils are the majority in the tea plantation sector. Furthermore, alcohol consumption is much higher in the tea plantation sector compared with the capital district, which is a factor known to be associated with DV. ${ }^{19} 20$

Among those who reported 'ever abused', only a small proportion had disclosed the abusive experience to a healthcare professional. The potential reason for this could be the acceptance of DV as a private matter due to the cultural and social norms. Compared with the capital district (13.3\%), disclosure was significantly lower among survivors in the tea plantation sector $(3.7 \%)$. This could also have resulted from the socioeconomic disparities in the two settings: lack of empowerment of the women and the language barriers.

Women who had 'ever been asked by a healthcare worker about abuse' were significantly higher in the capital district compared with the women in the tea plantation sector. The women in the tea plantation sector are highly exposed to many different health hazards compared with the women in the capital district. Thus, the healthcare worker must pay much more attention to other health priorities such as malnutrition and child and maternal mortality. Moreover, the healthcare worker in the capital district has more opportunities to be exposed to training and updates on recently introduced health priorities such as DV.

Although the distance from the GBV care centre did not have a significant correlation to 'not being asked by a healthcare worker about abuse', it did have a significant correlation to 'ever abused'. The capital district consisted of five functioning and accessible GBV care centres scattered throughout the district. In contrast to the capital district, in the tea plantation sector there was only one GBV care centre, and people were comparatively less exposed to the services offered by these centres. Furthermore, there was generally a lower awareness of DV. In the tea plantation sector, the language barrier could also have kept women in the tea plantation sector away from the care centre since service providers were incapable of communicating in Tamil. Future studies should focus on the evaluation of GBV care centres, in relation to public awareness, acceptability and accessibility as well as other important aspects in relation to the services.

This was a cross-sectional study; therefore, the temporal relationship between the correlations cannot be established. In a retrospective study design, low estimates due to recall bias are always possible and some may have purposefully blocked such thoughts due to stressful memories. Furthermore, under-reporting is possible due to sensitive nature of the topic under study. The under-reporting may be higher in sexual abuse than physical or psychological abuse due to stigma and cultural sensitivity. However, all possible measures were taken in this study to reduce under-reporting and therefore increase the comparability of the prevalence estimates.

As the study was conducted to represent all three major sectors, namely urban, rural and estate, with an adequate sample size and an appropriate sampling technique, the results can be generalised to currently pregnant women in similar settings in the country.

\section{CONCLUSION}

This study demonstrates the regional disparities of DV and the need for region-targeted interventions, considering the specific correlations. Findings show the urgent need for establishing accessible and user-friendly GBV care centres in the tea plantation sector. The capacity of healthcare workers in addressing DV, considering sociocultural factors of the two areas, should be increased.

The authors declared no potential conflicts of interest with respect to the research, authorship and/or publication of this article.

Acknowledgements The author acknowledge the Norwegian research council, the GLOBVAC program The Addressing Domestic Violence in Antenatal Care Environments (ADVANCE) research team includes the following research partners: At Norwegian university of science and technology (Norway): BS (Principal Investigator), Johan Håkon Bjørngaard, Elisabeth Darj, Jennifer J Infanti and Ragnhild Lund; at Oslo and Akershus university college (Norway): Mirjam Lukasse; at linneaus university, Kalmar (Sweden): KS at John hopkins university (USA): Jacquelyn C Campbell; at Kathmandu medical college and teaching hospital (Nepal): Sunil Kumar Joshi; at Dhulikhel hospital and Kathmandu university school of medical sciences (Nepal): Rajendra Koju, Kunta Devi Pun and at university of jayewardenepura (Sri Lanka): KW, DP and MMM.

Contributors MMM, DP, KW and KS planned the study. MMM, DP and KW collected the data. MMM, DP and KS analysed the data and drafted the manuscript. BS and $\mathrm{KW}$ assisted with the analysis. All authors contributed to the interpretation of the results and assisted in revising the manuscript. All authors have read and approved the final manuscript.

Funding This project was funded by the research council of Norway under its Global Health and Vaccination Research (GLOBVAC) program, project number 220893: 'Evaluating interventions in antenatal care to identify and assist victims of gender based violence in Nepal and Sri Lanka'.

Competing interests None declared.

Patient consent Obtained.

Ethics approval All methods, instruments and procedures were reviewed by the Ethical Review Committee of the Faculty of Medical Sciences, University of Sri Jayewardenepura, SriLanka in March 2014 (ref. no.: 07/14 and 08/14).

Provenance and peer review Not commissioned; externally peer reviewed.

Data sharing statement Unpublished additional data are available. Authors will analyse this for future publications. Only the authors can access the data. Others can access the data by contacting the authors.

Open Access This is an Open Access article distributed in accordance with the Creative Commons Attribution Non Commercial (CC BY-NC 4.0) license, which permits others to distribute, remix, adapt, build upon this work non-commercially, and license their derivative works on different terms, provided the original work is properly cited and the use is non-commercial. See: http://creativecommons.org/ licenses/by-nc/4.0/ 
(c) Article author(s) (or their employer(s) unless otherwise stated in the text of the article) 2018. All rights reserved. No commercial use is permitted unless otherwise expressly granted.

\section{REFERENCES}

1. WHO. Sri Lanka, Country policies and strategies for combating GBV. 2017 http://www.searo.who.int/entity/gender/data/sri_lanka.pdf.

2. Jayasuriya MVF. The prevalence and factors associated with intimate partner violence against women in the Western province. (MD thesis, Community Medicine), Postgraduate institute of Medicine. Colombo: University of Colombo, 2007.

3. Jayatilleke AC, Poudel KC, Yasuoka J, et al. Intimate partner violence in Sri Lanka. Biosci Trends 2010;4:90-5.

4. Wijayathilake K. Harsh realities: A pilot study on gender based violence in the plantations sector. Colombo: Plantation Human Development Trust, 2003.

5. Moonesinghe LN. The prevalence and correlates of physical abuse within marriage in a cohort of pregnant women in Badulla district. (MD thesis, Community Medicine), Postgraduate institute of Medicine. Colombo: University of Colombo, 2000.

6. Subramaniam P, Sivayogan S. The prevalence and pattern of wife beating in the Trincomalee district in eastern Sri Lanka. Southeast Asian J Trop Med Public Health 2001;32:186-95.

7. Deraniyagala S. An investigation into the incidence and causes of domestic violence in Colombo, Sri Lanka. Colombo: A Women In Need, 1992.

8. Samarasinghe G. Report on some observations on the incidence of domestic violence in four locations in Sri Lanka and the attitudes of women towards violence. Colombo: Women In Need, 1991.

9. Department of Census and Statistics. Census of Population and Housing. Colombo, Sri Lanka, 2012.
10. Medical Research Institute,. Nutrition and food security survey report 2009. Colombo: Medical Research Institute, Ministry of Health, 2010.

11. Department of census and statistics, Department of census and statistics in collaboration with Ministry of Health care and Nutrition. Sri Lanka demographic and health survey 2006/2007. Colombo, 2008.

12. FHB. Protocol for Gender-based Violence care centers. Colombo: Family Health Bureau, Ministry of Health Sri Lanka, 2012.

13. Center for Women's Research (CENWOR). Review of the implementation of Beijing Platform for Action- Sri Lanka- 1995-2014, 2015.

14. Colombini M, Mayhew S, Watts C. Health-sector responses to intimate partner violence in low- and middle-income settings: a review of current models, challenges and opportunities. Bull World Health Organ 2008;86:635-42.

15. UNFPA Asia and the Pacific Regional Office. Health sector response to gender-based violence Case Studies of the Asia Pacific region. Bangkok: UNFPA, 2010

16. Lwanga SK, Lemeshows S. Sample size determination in Health Studies, A Practical Manuel. Geneva: World Health Organization, 1991.

17. Bennett S, Woods T, Liyanage WM, et al. A simplified general method for cluster-sample surveys of health in developing countries. World Health Stat Q 1991;44:98-106.

18. Soeken K, McFarlane J, Parker B, et al. The Abuse Assessment Screen: A clinical instrument to measure frequency, severity, and perpetrator of abuse against women. Campbell JC, ed. Empowering survivors of abuse: Health care for battered women and their children. Thousand Oaks, CA: Sage, 1998.

19. Aheeyar MMM. Preliminary Investigation on the Issues Related to Poverty and Marginalization of Estate Sector Communities in Badulla and Nuwara Eliya Districts. Colombo: Practical action consulting, 2013

20. CEPA. Moving Out of Poverty in the Estate Sector in Sri Lanka. Colombo: Centre for Poverty Analysis, 2005. 